Check for updates

Cite this: RSC Adv., 2019, 9, 16683

Received 15th March 2019 Accepted 21st May 2019

DOI: 10.1039/c9ra02003a

rsc.li/rsc-advances

\section{Theoretical and experimental studies on hydrogen migration in dissociative ionization of the methanol monocation to molecular ions $\mathrm{H}_{3}^{+}$and $\mathrm{H}_{2} \mathrm{O}^{+}+{ }_{+}^{+}$}

\author{
Hua Wu, (D) *a Yuanxin Xue, Junqing Wen, (D) ' Hui Wang, ${ }^{a}$ Qingfei Fan, ${ }^{b}$ \\ Guoxiang Chen, ${ }^{a}$ Jin Zhu, ${ }^{a}$ Fanghui $\mathrm{Qu}^{\mathrm{a}}$ and Jiale Guo ${ }^{\mathrm{a}}$
}

\begin{abstract}
The dissociative ionization processes of the methanol monocation $\mathrm{CH}_{3} \mathrm{OH}^{+}$to $\mathrm{H}_{3}^{+}+\mathrm{CHO}$ and $\mathrm{H}_{2} \mathrm{O}^{+}+\mathrm{CH}_{2}$ are studied by ab initio method, and hydrogen migration processes are confirmed in these two dissociation processes. Due to the positive charge assignment in dissociation processes, the fragmentation pathways of $\mathrm{CH}_{3} \mathrm{OH}^{+}$to $\mathrm{H}_{3}+\mathrm{CHO}^{+}$and $\mathrm{CH}_{3} \mathrm{OH}^{+}$to $\mathrm{H}_{2} \mathrm{O}+\mathrm{CH}_{2}{ }^{+}$are also calculated. The calculation results show that a neutral $\mathrm{H}_{2}$ moiety in the methanol monocation $\mathrm{CH}_{3} \mathrm{OH}^{+}$is the origin of the formation of $\mathrm{H}_{3}{ }^{+}$, and the ejection of fragment ions $\mathrm{H}_{3}^{+}$and $\mathrm{H}_{2} \mathrm{O}^{+}$is more difficult than $\mathrm{CHO}^{+}$and $\mathrm{CH}_{2}^{+}$respectively. Experimentally, by using a dc-slice imaging technique under an $800 \mathrm{~nm}$ femtosecond laser field, the velocity distributions of fragment ions $\mathrm{H}_{3}{ }^{+}, \mathrm{CHO}^{+}, \mathrm{CH}_{2}{ }^{+}$, and $\mathrm{H}_{2} \mathrm{O}^{+}$are calculated from their corresponding sliced images. The presence of low-velocity components of these four fragment ions confirms that the formation of these ions is not from the Coulomb explosion of the methanol dication. Hence, the four hydrogen migration pathways from the methanol monocation $\mathrm{CH}_{3} \mathrm{OH}^{+}$to $\mathrm{H}_{3}{ }^{+}+\mathrm{CHO}_{\text {, }}$ $\mathrm{CHO}^{+}+\mathrm{H}_{3}, \mathrm{H}_{2} \mathrm{O}^{+}+\mathrm{CH}_{2}$, and $\mathrm{CH}_{2}^{+}+\mathrm{H}_{2} \mathrm{O}$ are securely confirmed. It can be observed in the time-offlight mass spectrum of ionization and dissociation of methanol that the ion yields of fragment ions $\mathrm{H}_{3}^{+}$ and $\mathrm{H}_{2} \mathrm{O}^{+}$are lower than $\mathrm{CHO}^{+}$and $\mathrm{CH}_{2}{ }^{+}$respectively, which is consistent with the theoretical results according to which dissociation from the methanol monocation to $\mathrm{H}_{3}{ }^{+}$and $\mathrm{H}_{2} \mathrm{O}^{+}$is more difficult than $\mathrm{CHO}^{+}$and $\mathrm{CH}_{2}{ }^{+}$respectively.
\end{abstract}

\section{Introduction}

When exposed to an intense femtosecond laser field, neutral hydrocarbon molecules can experience a variety of dynamical processes such as multiple ionization, dissociative ionization (DI), Coulomb explosion (CE), and chemical bond rearrangement. ${ }^{1-7}$ Among these dynamical processes, the intramolecular hydrogen migration process, leading to large-scale chemical bond rearrangement processes, has been an attractive research subject both experimentally and theoretically during the last several years. ${ }^{3-7}$ For example, $\mathrm{Xu}$ and co-workers experimentally observed the singly charged fragment ions $\mathrm{CH}_{3}{ }^{+}$and $\mathrm{C}_{2} \mathrm{H}_{3}{ }^{+}$in the two-body CE processes of allene dication: $\mathrm{C}_{3} \mathrm{H}_{4}{ }^{2+} \rightarrow \mathrm{CH}_{3}{ }^{+}+$ $\mathrm{C}_{2} \mathrm{H}^{+}$and $\mathrm{C}_{3} \mathrm{H}_{4}{ }^{2+} \rightarrow \mathrm{C}_{2} \mathrm{H}_{3}^{+}+\mathrm{CH}^{+}$, which confirmed that hydrogen atom or proton migrated from the methylene groups. ${ }^{7}$ Weitzel and co-workers experimentally observed the pathway

${ }^{a}$ School of Sciences, Xi'an Shiyou University, Shanxi 710065, P. R. China. E-mail: whua@xsyu.edu.cn

${ }^{b}$ State Key Laboratory of Precision Spectroscopy, School of Physics and Materials, East China Normal University, Shanghai 200062, P. R. China

$\dagger$ PACS numbers: 31.15.A-, 82.30.Hk, 33.80.Rv, 82.53.St.

\$ Electronic supplementary information (ESI) available. See DOI: 10.1039/c9ra02003a
$\mathrm{C}_{2} \mathrm{H}_{6}{ }^{2+} \rightarrow \mathrm{C}_{2} \mathrm{H}_{3}{ }^{+}+\mathrm{H}_{3}{ }^{+}$, and then demonstrated that hydrogen migration process was involved in this dissociation process and the dissociation pathway took place on the potential energy surface (PES) of ethane dication by employing quantum chemical calculations. ${ }^{3}$ Yamanouchi and co-workers demonstrated in their experimental and theoretical studies that hydrogen migration played a decisive role in the breaking and rearrangement processes of chemical bonds in hydrocarbon molecules. ${ }^{6-8}$

Methanol is the simplest alcohol, consisting of a methyl group linked to a hydroxyl group. A methanol molecule contains one carbon atom, one oxygen atom and four hydrogen atoms, so hydrogen migration processes within the fragmentation of methanol can be extensively observed. ${ }^{9-21}$ There are generally two typical hydrogen migration processes involved in methanol: the ejection of triatomic hydrogen molecular ion $\mathrm{H}_{3}{ }^{+}$from methanol involves breaking of at least three chemical bond ( $\mathrm{C}-$ $\mathrm{H}$ and $\mathrm{O}-\mathrm{H}$ ) and formation of three new $\mathrm{H}-\mathrm{H}$ bond, and hydrogen migration may be involved in this complex process; the generation of water molecular ion $\mathrm{H}_{2} \mathrm{O}^{+}$from methanol involves the migration of one hydrogen atom from methyl group to hydroxyl group. ${ }^{9-21}$ Safvan and co-workers observed $\mathrm{H}_{3}{ }^{+}$ ion from $\mathrm{CE}$ of methanol dication $\left(\mathrm{CH}_{3} \mathrm{OH}^{2+} \rightarrow \mathrm{H}_{3}^{+}+\mathrm{CHO}^{+}\right)$ under the impact of low energy $\mathrm{Ar}^{8+}$ projectiles, and established 
that $\mathrm{H}_{3}{ }^{+}$formation arised from intramolecular bond rearrangement of the methyl group. ${ }^{9}$ Yamanouchi and co-workers designed a series of experiments on methanol $\mathrm{CH}_{3} \mathrm{OH}$ and its isotopomers $\mathrm{CH}_{3} \mathrm{OD}$ and $\mathrm{CD}_{3} \mathrm{OH}$ by coincidence momentum imaging method. Fragment ions $\mathrm{H}_{2} \mathrm{O}^{+}, \mathrm{HDO}^{+}, \mathrm{H}_{2} \mathrm{D}^{+}$, and $\mathrm{D}_{2} \mathrm{H}^{+}$ were securely identified, and thus they confirmed that hydrogen migration processes existed in these four $\mathrm{CE}$ process of $\mathrm{CH}_{3} \mathrm{OH}^{2+} \rightarrow \mathrm{H}_{2} \mathrm{O}^{+}+\mathrm{CH}_{2}{ }^{+}, \mathrm{CH}_{3} \mathrm{OD}^{2+} \rightarrow \mathrm{HDO}^{+}+\mathrm{CH}_{2}{ }^{+}, \mathrm{CH}_{3} \mathrm{OD}^{2+}$ $\rightarrow \mathrm{H}_{2} \mathrm{D}^{+}+\mathrm{CHO}^{+}$, and $\mathrm{CD}_{3} \mathrm{OH}^{2+} \rightarrow \mathrm{D}_{2} \mathrm{H}^{+}+\mathrm{CDO}^{+}$, and they found that the yield of hydrogen migration pathway $\mathrm{CH}_{3} \mathrm{OH}^{2+}$ $\rightarrow \mathrm{H}_{2} \mathrm{O}^{+}+\mathrm{CH}_{2}^{+}$could be affected by laser parameters such as pulse duration, laser intensity and laser polarization direction. ${ }^{\mathbf{1 0 - 1 3}}$ Very recently, they studied the yield of $\mathrm{H}_{3}{ }^{+}$by pumpprobe measurements, and showed that the yield of $\mathrm{H}_{3}{ }^{+}$was enhanced each time when the vibrational wave packet coming back to the inner turning point of methanol cation was projected onto the dication potential energy surface. ${ }^{\mathbf{1 4}}$ Theoretically, Yamanouchi and co-workers revealed that a long lived neutral $\mathrm{D}_{2}$ moiety in methanol dication $\mathrm{CD}_{3} \mathrm{OH}^{2+}$ was the origin to the formation of $\mathrm{H}_{2} \mathrm{D}^{+}$and $\mathrm{D}_{3}{ }^{+}\left(\mathrm{CH}_{3} \mathrm{OD}^{2+} \rightarrow \mathrm{H}_{2} \mathrm{D}^{+}+\mathrm{CHO}^{+}\right.$ and $\mathrm{CH}_{3} \mathrm{OD}^{2+} \rightarrow \mathrm{D}_{3}^{+}+\mathrm{CHO}^{+}$) by first-principle molecular dynamics simulation. ${ }^{15}$ More recently, Dantus and co-workers found two reaction pathways for the formation of $\mathrm{H}_{3}{ }^{+}$from methanol dication under strong-field ionization. Then they demonstrated that the $\mathrm{H}_{3}{ }^{+}$formation from a series of doubly charged alcohols proceeded through a roaming neutral $\mathrm{H}_{2}$ moiety, and found that the yield of $\mathrm{H}_{3}{ }^{+}$decreased as the carbon chain length increased. ${ }^{\mathbf{1 6}, 17}$ Radom and co-workers reported theoretically that $\mathrm{CH}_{2} \mathrm{OH}_{2}{ }^{+}$was a stable isomer of $\mathrm{CH}_{3} \mathrm{OH}^{+}$, and calculated the dissociation pathway of $\mathrm{CH}_{3} \mathrm{OH}^{+} \rightarrow \mathrm{H}_{2} \mathrm{O}+$ $\mathrm{CH}_{2}{ }^{+}{ }^{18,19}$ Later, they verified that $\mathrm{CH}_{2} \mathrm{OH}_{2}{ }^{+}$was a stable, observable gas-phase species in experiment, and found that the energy gap between the two stable structures of $\mathrm{CH}_{3} \mathrm{OH}^{+}$and $\mathrm{CH}_{2} \mathrm{OH}_{2}{ }^{+}$connected by a hydrogen migration process was about $0.33 \mathrm{eV}^{19,20}$ Schlegel and co-workers studied the potential energy surfaces for the isomerization and fragmentation of $\mathrm{CH}_{3} \mathrm{OH}^{2+} \rightarrow \mathrm{H}_{2} \mathrm{O}^{+}+\mathrm{CH}_{2}^{+}$and $\mathrm{CH}_{3} \mathrm{OH}^{+} \rightarrow \mathrm{H}_{2} \mathrm{O}+\mathrm{CH}_{2}^{+}$, and their calculated kinetic energy releases were in good accordance with Yamanouchi and co-workers' experimental observations. ${ }^{21}$

Most of the above studies showed that hydrogen migration processes were confirmed in CE processes of methanol dication to triatomic molecular ion $\mathrm{H}_{3}{ }^{+}$. However, to the best of our knowledge, whether such migration processes can happen in the methanol monocation were rarely studied. In this paper, we demonstrate that such hydrogen migration processes can happen in the methanol monocation. We present a combined theoretical and experimental study on hydrogen migration in DI process of methanol monocation $\mathrm{CH}_{3} \mathrm{OH}^{+}$to molecular ions $\mathrm{H}_{3}{ }^{+}$and $\mathrm{H}_{2} \mathrm{O}^{+}$. Firstly, the complete reaction path on ground electronic state PES of $\mathrm{CH}_{3} \mathrm{OH}^{+}$to molecular ions $\mathrm{H}_{3}{ }^{+}$and $\mathrm{H}_{2} \mathrm{O}^{+}$ have been performed at the level of B3LYP/6-311++G (d, p) by Gaussian 09 package. Hydrogen migration processes are confirmed in these two dissociation processes of $\mathrm{CH}_{3} \mathrm{OH}^{+}$to $\mathrm{H}_{2} \mathrm{O}^{+}+\mathrm{CH}_{2}$ and $\mathrm{H}_{3}{ }^{+}+\mathrm{CHO}$. For dissociation processes of $\mathrm{CH}_{3} \mathrm{OH}^{+} \rightarrow \mathrm{H}_{3}{ }^{+}+\mathrm{CHO}$ and $\mathrm{CH}_{3} \mathrm{OH}^{+} \rightarrow \mathrm{H}_{2} \mathrm{O}^{+}+\mathrm{CH}_{2}$, the positive charge can assign to either part. Therefore, dissociation processes of $\mathrm{CH}_{3} \mathrm{OH}^{+} \rightarrow \mathrm{H}_{3}^{+}+\mathrm{CHO}$ and $\mathrm{CH}_{3} \mathrm{OH}^{+} \rightarrow \mathrm{H}_{2} \mathrm{O}+$
$\mathrm{CH}_{2}{ }^{+}$are also calculated. The results show that a neutral $\mathrm{H}_{2}$ moiety in methanol monocation $\mathrm{CH}_{3} \mathrm{OH}^{+}$is the origin to the formation of $\mathrm{H}_{3}{ }^{+}$, and dissociation to fragment ions $\mathrm{H}_{3}{ }^{+}$and $\mathrm{H}_{2} \mathrm{O}^{+}$are more difficult than that of $\mathrm{CHO}^{+}$and $\mathrm{CH}_{2}^{+}$respectively. Then, time-of-flight mass spectra (TOF-MS) of ionization and dissociation of methanol induced by femtosecond laser field are obtained. Four fragment ions $\mathrm{H}_{3}{ }^{+}, \mathrm{CHO}^{+}, \mathrm{H}_{2} \mathrm{O}^{+}$and $\mathrm{CH}_{2}{ }^{+}$are all detected, and the ion yield of fragment ions $\mathrm{H}_{3}{ }^{+}$and $\mathrm{H}_{2} \mathrm{O}^{+}$are lower than that of $\mathrm{CH}_{2}^{+}$and $\mathrm{CHO}^{+}$respectively, which is consistent with our calculation results. At last, the sliced images of fragment ions $\mathrm{H}_{3}{ }^{+}, \mathrm{CHO}^{+}, \mathrm{H}_{2} \mathrm{O}^{+}$and $\mathrm{CH}_{2}{ }^{+}$are measured under $800 \mathrm{~nm}$ femtosecond laser field by dc-slice imaging technique, ${ }^{22}$ and their corresponding velocity distributions are extracted and calculated. The presence of lowvelocity components of these four fragment ions confirms that the formation of these ions are not from $\mathrm{CE}$ of methanol dication. Hence, fragment ions $\mathrm{H}_{3}{ }^{+}, \mathrm{CH}_{2}{ }^{+}, \mathrm{H}_{2} \mathrm{O}^{+}$, and $\mathrm{CHO}^{+}$are confirmed to arise from methanol monocation.

\section{Computational details}

$A b$ initio calculations for hydrogen migration processes in DI of methanol monocation $\mathrm{CH}_{3} \mathrm{OH}^{+}$to molecular ions $\mathrm{H}_{3}{ }^{+}, \mathrm{CHO}^{+}$, $\mathrm{H}_{2} \mathrm{O}^{+}$and $\mathrm{CH}_{2}{ }^{+}$were carried out by Gaussian 09 programs. ${ }^{23}$ The four dissociation pathways were calculated on the ground doublet PES of methanol monocation $\mathrm{CH}_{3} \mathrm{OH}^{+}$. Various isomers of methanol monocation, transition states (TSs) and fragmentation products have been fully optimized at B3LYP/6-311++G (d, p) level of theory. ${ }^{\mathbf{2 4 , 2 5}}$ Vibrational frequencies were computed at the same B3LYP/6-311++G (d, p) level to obtain zero point energies and to confirm that the structures were either minima or transition state (the number of imaginary frequencies NIMAG $=0$ and 1 for the local minima and the transition state, respectively). All the energies quoted in the text were further refined by $\operatorname{CCSD}(\mathrm{T}) / \mathrm{cc}-\mathrm{PVTZ}$ with B3LYP/6-311++G (d, p) zeropoint energy (ZPE). The intrinsic-reaction-coordinate (IRC) calculations at the same level of theory were carried out to track the minimum energy paths from the transition states to the corresponding minima.

\section{Experimental section}

The experimental setup has been described in our previous paper, ${ }^{\mathbf{4} 26,27}$ and the more detailed information can be seen in "ESI+". Briefly, femtosecond laser pulses (800 nm, $1 \mathrm{kHz}, 120 \mathrm{fs}$ ) were focused by a quartz lens onto a molecular beam of methanol (Sinopharm Chemical Reagent Co., Ltd, anhydrous grade, $99.9+\%$ purity) in an ultrahigh vacuum chamber. Methanol molecules were seeded into the chamber by gaseous helium and injected into ionization region by a pulse valve with repetition rate of $100 \mathrm{~Hz}$. The generated fragment ions were accelerated and detected by microchannel plates coupled to a phosphor screen, and finally their intensities were detected by a photomultiplier tube and their spatial distributions were imaged by an intensified charge coupled device camera. All the timing sequence was controlled by a digital delay pulse generator (DG535). 


\section{Results and discussions}

This section is organized as follows: we firstly calculate the dissociation pathways of methanol monocation $\mathrm{CH}_{3} \mathrm{OH}^{+}$to molecular ions $\mathrm{H}_{3}{ }^{+}$and $\mathrm{H}_{2} \mathrm{O}^{+}$by Gaussian 09 programs at B3LYP/6-311++G (d, p) level, and hydrogen migration processes are confirmed in these two dissociation processes of $\mathrm{CH}_{3} \mathrm{OH}^{+}$to $\mathrm{H}_{3}{ }^{+}+\mathrm{CHO}$ and $\mathrm{H}_{2} \mathrm{O}^{+}+\mathrm{CH}_{2}$. Due to the positive charge assignment in dissociation process, fragmentation pathways of $\mathrm{CH}_{3} \mathrm{OH}^{+}$to $\mathrm{H}_{3}+\mathrm{CHO}^{+}$and $\mathrm{H}_{2} \mathrm{O}+\mathrm{CH}_{2}{ }^{+}$are also calculated. The results show that a neutral $\mathrm{H}_{2}$ moiety in methanol monocation $\mathrm{CH}_{3} \mathrm{OH}^{+}$is the origin to the formation of $\mathrm{H}_{3}{ }^{+}$, and dissociation of $\mathrm{CH}_{3} \mathrm{OH}^{+}$to fragment ions $\mathrm{H}_{3}{ }^{+}$and $\mathrm{H}_{2} \mathrm{O}^{+}$are more difficult than that of $\mathrm{CHO}^{+}$and $\mathrm{CH}_{2}{ }^{+}$respectively. Then, time-of-flight mass spectrum of methanol induced by femtosecond laser field is obtained. Fragment ions $\mathrm{H}_{3}{ }^{+}, \mathrm{CHO}^{+}, \mathrm{H}_{2} \mathrm{O}^{+}$and $\mathrm{CH}_{2}{ }^{+}$can be detected in the mass spectrum, and it can be seen that the ion yield of fragment ions $\mathrm{H}_{3}{ }^{+}$and $\mathrm{H}_{2} \mathrm{O}^{+}$are lower than that of $\mathrm{CH}_{2}^{+}$and $\mathrm{CHO}^{+}$, which is consistent with the calculation results. At last, dissociation processes of methanol are studied under $800 \mathrm{~nm}$ femtosecond laser field by dc-slice imaging technique. The sliced images of fragment ions $\mathrm{H}_{3}{ }^{+}, \mathrm{CHO}^{+}, \mathrm{H}_{2} \mathrm{O}^{+}$ and $\mathrm{CH}_{2}{ }^{+}$are measured, their corresponding velocity distributions are extracted and calculated, and the presence of lowvelocity of these four fragment ions explains that four DI pathways of methanol monocation $\mathrm{CH}_{3} \mathrm{OH}^{+}$to $\mathrm{H}_{3}{ }^{+}, \mathrm{CHO}^{+}, \mathrm{H}_{2} \mathrm{O}^{+}$ and $\mathrm{CH}_{2}{ }^{+}$exist in the experiment.

\subsection{Dissociation pathways of $\mathrm{CH}_{3} \mathrm{OH}^{+}$to $\mathrm{H}_{3}{ }^{+}, \mathrm{CHO}^{+}, \mathrm{H}_{2} \mathrm{O}^{+}$ and $\mathrm{CH}_{2}{ }^{+}$by ab initio calculations}

The complete reaction paths from the stable structure of methanol monocation $\mathrm{CH}_{3} \mathrm{OH}^{+}$to $\mathrm{H}_{3}{ }^{+}+\mathrm{CHO}$ and $\mathrm{H}_{2} \mathrm{O}^{+}+\mathrm{CH}_{2}$ are calculated on the ground doublet PES of $\mathrm{CH}_{3} \mathrm{OH}^{+}$at $\mathrm{B} 3 \mathrm{LYP} /$ 6-311++G (d, p) level of theory, as shown in Fig. 1. The relevant structures of various methanol isomers are shown in Fig. 2. For dissociation of $\mathrm{CH}_{3} \mathrm{OH}^{+}$to $\mathrm{H}_{3}{ }^{+}+\mathrm{CHO}$, hydrogen atom in $\mathrm{OH}$ group migrates from oxygen atom towards carbon atom to form TS1, and followed by the asynchronous movement of this $\mathrm{H}$

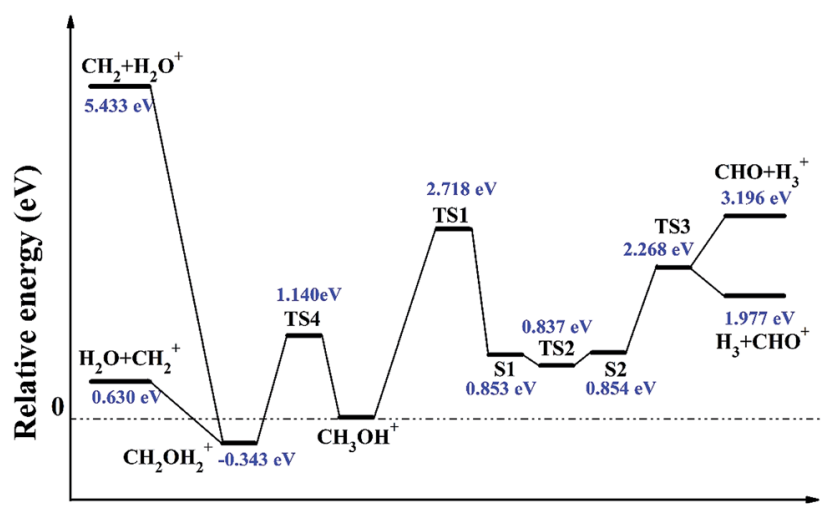

Reaction Coordinates

Fig. 1 The reaction pathways of $\mathrm{CH}_{3} \mathrm{OH}^{+}$to fragment ions $\mathrm{H}_{3}{ }^{+}, \mathrm{CHO}^{+}$, $\mathrm{H}_{2} \mathrm{O}^{+}$and $\mathrm{CH}_{2}{ }^{+}$. The various geometries are optimized at the level of $B 3 L Y P / 6-311++G(d, p)$, the energies are further refined by $\operatorname{CCSD}(T) /$ cc-pVTZ with B3LYP/6-311++G (d, p) zero-point energy corrections. atom and the nearby $\mathrm{H}$ atom far away from $\mathrm{C}$ atom to form $\mathrm{S} 1$. The energy barrier between $\mathrm{CH}_{3} \mathrm{OH}^{+}$and TS1 is $2.718 \mathrm{eV}$, and the energy gap between $\mathrm{CH}_{3} \mathrm{OH}^{+}$and $\mathrm{S} 1$ is $0.853 \mathrm{eV}$. In $\mathrm{S} 1$ structure, a new $\mathrm{H}-\mathrm{H}$ chemical bond is formed to become a nearly neutral $\mathrm{H}_{2}$ moiety which seemingly separated from the rest of the molecule, and the two $\mathrm{C}-\mathrm{H}$ bond length are both 2.58 $\AA$. Then, the $\mathrm{H}_{2}$ moiety moves towards the hydrogen atom 3 , and the degree of angle $\angle 123$ keeps declining from $78^{\circ}$ in $\mathrm{S} 1$ to $7^{\circ}$ to form S2 by surpassing TS2 in which the degree of angle $\angle 123$ is $51^{\circ}$. It is noticeable that the energy of TS2 is $0.016 \mathrm{eV}$ lower than that of S1, and this common phenomenon have been demonstrated in previous studies. ${ }^{28-30}$ That is to say, $\mathrm{S} 1$ is trapped in a very shallow quasi-bound well of the potential energy surface, and can produce a barrierless reaction process. Finally, S2 surpasses TS3 with an energy barrier of $2.268 \mathrm{eV}$ to produce $\mathrm{H}_{3}{ }^{+}$ + CHO. Besides, the PES along the $\mathrm{R}\left(\mathrm{CHO} \cdots \mathrm{H}_{3}{ }^{+}\right)$-coordinate show that in S1, TS2, and S2, the sum of the atomic charges of the two $\mathrm{H}$ atoms 1 and 4 are found to be very close to zero. This demonstrate that a neutral $\mathrm{H}_{2}$ moiety in methanol monocation $\mathrm{CH}_{3} \mathrm{OH}^{+}$is the origin to the formation of $\mathrm{H}_{3}{ }^{+}$, which is consistent with the conclusion by Yamanouchi et al. and Dantus et al. that "The formation of $\mathrm{H}_{3}{ }^{+}$from methanol dication proceeded through a roaming neutral $\mathrm{H}_{2}$ moiety"15-17 For dissociation of $\mathrm{CH}_{3} \mathrm{OH}^{+}$to $\mathrm{H}_{2} \mathrm{O}^{+}+\mathrm{CH}_{2}$, the hydrogen migration within $\mathrm{CH}_{3} \mathrm{OH}^{+}$ from methyl group to hydroxyl group through TS4 can lead to $\mathrm{CH}_{2} \mathrm{OH}_{2}{ }^{+}$. This process should surpass an energy barrier of $1.140 \mathrm{eV}$, and then dissociates into $\mathrm{CH}_{2}+\mathrm{H}_{2} \mathrm{O}^{+}$. Our calculated energy gap between structures of $\mathrm{CH}_{3} \mathrm{OH}^{+}$and $\mathrm{CH}_{2} \mathrm{OH}_{2}{ }^{+}$is close to that of Radom's. ${ }^{12,13,15}$ The IRC calculations at the same level of theory show that TS1, TS2, TS3, and TS4 are the right transition states to their corresponding minima.

For dissociation processes of methanol monocation $\mathrm{CH}_{3} \mathrm{OH}^{+}$ to $\mathrm{H}_{3}{ }^{+}+\mathrm{CHO}$ and $\mathrm{H}_{2} \mathrm{O}^{+}+\mathrm{CH}_{2}$, the positive charge can assign to either part. Therefore, dissociation processes of $\mathrm{CH}_{3} \mathrm{OH}^{+}$to $\mathrm{H}_{3}+$ $\mathrm{CHO}^{+}$and $\mathrm{H}_{2} \mathrm{O}+\mathrm{CH}_{2}{ }^{+}$are also calculated, as can be seen in Fig. 1. Compared to dissociation processes of methanol monocation $\mathrm{CH}_{3} \mathrm{OH}^{+}$to $\mathrm{H}_{3}{ }^{+}+\mathrm{CHO}$ and $\mathrm{H}_{2} \mathrm{O}^{+}+\mathrm{CH}_{2}$, the dissociation to $\mathrm{CHO}^{+}+\mathrm{H}_{3}$ and $\mathrm{H}_{2} \mathrm{O}+\mathrm{CH}_{2}^{+}$are preferred.

Density functional (B3LYP) level of theory has proven to be a successful tool for the calculations of hydrogen migration pathways from hydrocarbon molecules, and a lot of groups have adopted B3LYP method to explain their corresponding experimental phenomena efficiently. ${ }^{14,34-37}$ Moreover, in order to check on the accuracy of our calculations, we also calculate the dissociation pathways of $\mathrm{CH}_{3} \mathrm{OH}^{+}$to $\mathrm{CH}_{2}+\mathrm{H}_{2} \mathrm{O}^{+}, \mathrm{CH}_{2}{ }^{+}+\mathrm{H}_{2} \mathrm{O}$, $\mathrm{COH}^{+}+\mathrm{H}_{3}$ and $\mathrm{COH}+\mathrm{H}_{3}{ }^{+}$using MP2 level of theory at 6-311++G $(\mathrm{d}, \mathrm{p})$ basis set. The calculation results are in accordance with the previous calculations carried out at B3LYP/6-311++G $(\mathrm{d}, \mathrm{p})$ level (see ESIt).

\subsection{TOF-MS by ionization and dissociation of methanol}

The TOF mass spectrum of ion species generated by ionization of $\mathrm{CH}_{3} \mathrm{OH}$ molecules with intense femtosecond laser pulses at an intensity of $1.2 \times 10^{14} \mathrm{~W} \mathrm{~cm}^{-2}$ is shown in Fig. 3. The laser polarization direction is kept perpendicular to the TOF axis by a half-wave plate. The fragment ion with $m / z=3$ is observed and 


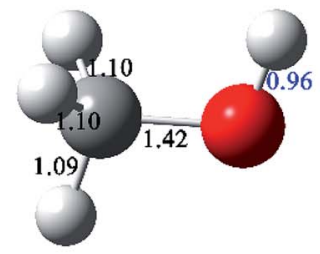

(a) $\mathrm{CH}_{3} \mathrm{OH}$

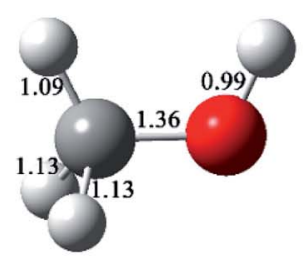

(b) $\mathrm{CH}_{3} \mathrm{OH}^{+}$

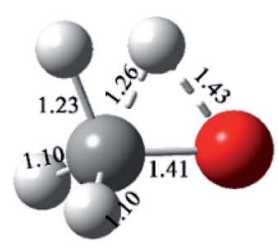

(c) TS1

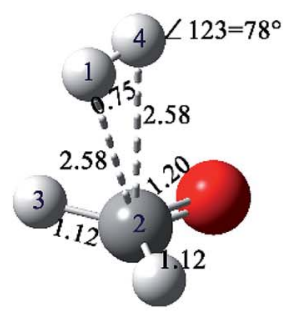

(d) S1

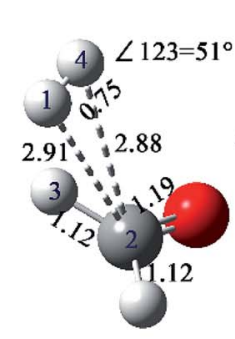

(e) TS2

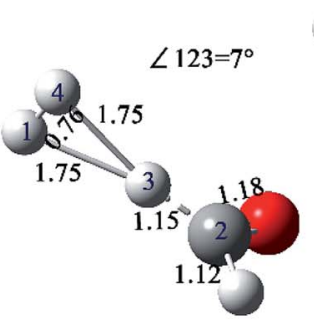

(f) $\mathrm{S} 2$

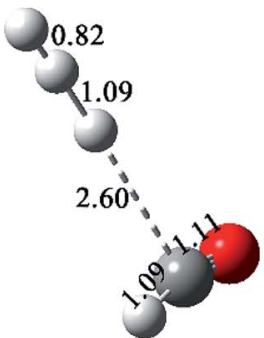

(g) TS3

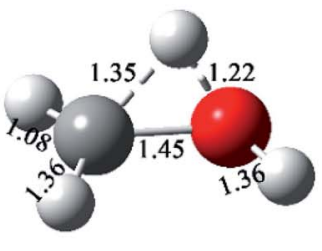

(h) TS4

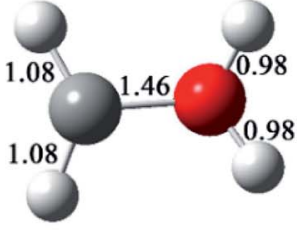

(i) $\mathrm{CH}_{2} \mathrm{OH}_{2}{ }^{+}$

Fig. 2 Structures of $\mathrm{CH}_{3} \mathrm{OH}, \mathrm{CH}_{3} \mathrm{OH}^{+}, \mathrm{TS} 1, \mathrm{~S} 1, \mathrm{TS} 2, \mathrm{~S} 2, \mathrm{TS} 3, \mathrm{TS} 4$, and $\mathrm{CH}_{2} \mathrm{OH}_{2}{ }^{+}$((a) - (i)), optimized at the theoretical level of B3LYP/6-311++ G (d, p). The decimals represent the bond length of the corresponding chemical bond, and their units are in $\AA$.

assigned to the molecular ion $\mathrm{H}_{3}{ }^{+}$instead of $\mathrm{C}^{4+}$ for the absence of $\mathrm{C}^{3+}$, whose appearance energy is generally lower than that of $\mathrm{C}^{4+}$. Based on the following three points, we deduce that $\mathrm{H}_{2} \mathrm{O}^{+}$ molecular ions are from dissociation of methanol monocation rather than the impurity $\mathrm{H}_{2} \mathrm{O}$ : (1) the methanol sample we customized is anhydrous grade, $99.9+\%$ purity. (2) TOF spectrum in this paper is treated for background subtraction, in order to eliminate the impact from impurities and water in the cavity. (3) The pump-probe experiments by $\mathrm{Xu}$ and coauthors ${ }^{12,13}$ showed indirectly that $\mathrm{H}_{2} \mathrm{O}^{+}$molecular ions could be produced from methanol monocation. The observation of fragment ion $\mathrm{H}_{2} \mathrm{O}^{+}$shows that hydrogen migration occurs in

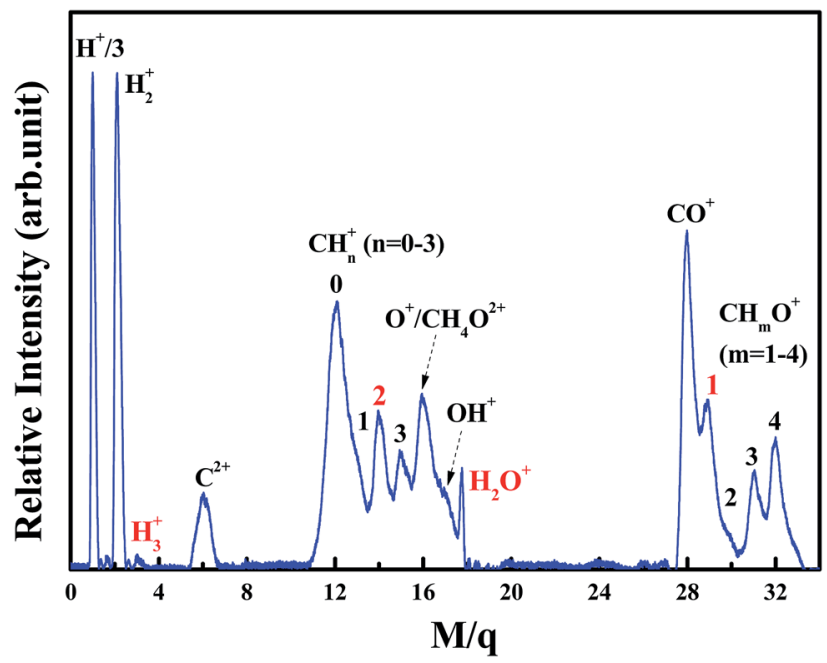

Fig. 3 TOF mass spectrum of ion species generated by the ionization of methanol with intense femtosecond laser pulses at laser intensity of $1.2 \times 10^{14} \mathrm{~W} \mathrm{~cm}^{-2}$. fragmentation process of methanol, since no " $\mathrm{H}_{2} \mathrm{O}$ " group is involved in methanol. Besides, fragment ions $\mathrm{CHO}^{+}$and $\mathrm{CH}_{2}{ }^{+}$ can also be observed in the mass spectrum. Thus, four fragment ions $\mathrm{H}_{3}{ }^{+}, \mathrm{CHO}^{+}, \mathrm{H}_{2} \mathrm{O}^{+}$and $\mathrm{CH}_{2}{ }^{+}$(marked with red color in Fig. 3) are all securely confirmed in the mass spectrum. In addition, various atomic and fragment ion species, such as $\mathrm{H}^{+}, \mathrm{H}_{2}{ }^{+}, \mathrm{C}^{2+}$, $\mathrm{CH}^{+}, \mathrm{O}^{+} / \mathrm{CH}_{4} \mathrm{O}^{2+}$, and $\mathrm{CH}_{m} \mathrm{O}^{+}(m=2-4)$ are detected, showing that significant fragmentation proceeds in dissociative ionization process of methanol. It can be calculated from Fig. 3 that the relative yield of these four fragment ions $\mathrm{H}_{3}{ }^{+}, \mathrm{CHO}^{+}, \mathrm{H}_{2} \mathrm{O}^{+}$, and $\mathrm{CH}_{2}{ }^{+}$(obtained by the ratio of the corresponding ion signal to the total ion signals in TOF mass spectrum) are calculated to be $0.4 \%, 7.0 \%, 1.3 \%$, and $7.8 \%$ respectively. These relative yields contain ion signals from both DI and CE processes, so the yield of these four fragment ions from DI can't be compared because of the unknown yield of these fragment ions from CE. However, it can still be obtained that ion yield of fragment ions $\mathrm{H}_{3}{ }^{+}$and $\mathrm{H}_{2} \mathrm{O}^{+}$from DI are lower than that of fragment ions $\mathrm{CHO}^{+}$and $\mathrm{CH}_{2}{ }^{+}$from DI respectively. This is in accordance with our theoretical results that fragment ions $\mathrm{H}_{3}{ }^{+}$and $\mathrm{H}_{2} \mathrm{O}^{+}$are more difficult to occur than $\mathrm{CHO}^{+}$and $\mathrm{CH}_{2}{ }^{+}$in the dissociation process. The features of the observed mass spectrum are in accordance with the previous study. ${ }^{31}$

\subsection{DI of $\mathrm{CH}_{3} \mathrm{OH}^{+}$to $\mathrm{H}_{3}{ }^{+}$and $\mathrm{H}_{2} \mathrm{O}^{+}$by de-slice imaging technique}

As well known, dc slice imaging technique can provide a wellestablished method to discriminate dissociation channels of the fragment ions. To demonstrate the dissociation process of fragment ions $\mathrm{H}_{3}{ }^{+}, \mathrm{CHO}^{+}, \mathrm{H}_{2} \mathrm{O}^{+}$and $\mathrm{CH}_{2}{ }^{+}$, we present the dcsliced ion images of fragment ions $\mathrm{H}_{3}{ }^{+}, \mathrm{CHO}^{+}, \mathrm{H}_{2} \mathrm{O}^{+}$and $\mathrm{CH}_{2}{ }^{+}$ at laser intensity of $1.2 \times 10^{14} \mathrm{~W} \mathrm{~cm}^{-2}$, as shown in Fig. 4 . The 

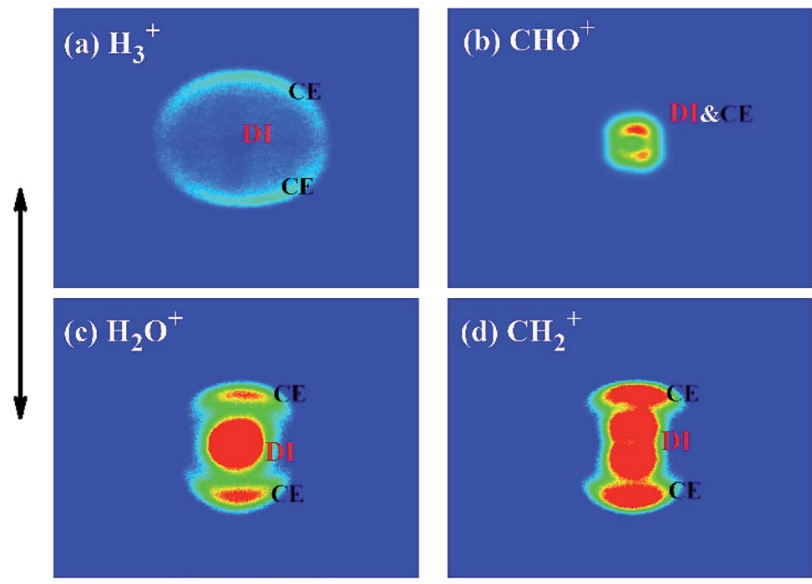

Fig. 4 Dc sliced images of fragment ions $\mathrm{H}_{3}{ }^{+}, \mathrm{CHO}^{+}, \mathrm{H}_{2} \mathrm{O}^{+}$and $\mathrm{CH}_{2}{ }^{+}$ ((a)-(d)) at laser intensity of $1.2 \times 10^{14} \mathrm{~W} \mathrm{~cm}^{-2}$. The black doubleheaded arrow beside the images represents the laser polarization direction.

corresponding velocity distributions of these fragment ions are shown in Fig. 5. All velocity distributions are fitted with multiple Gaussian functions, and peak KER values of the fitted Gaussian components are labeled. It can be seen that all the fragment ions are composed of both high- and low-KER components. It is obvious that fragment ions with high KER should result from CE process according to the law of momentum conservation, which are not discussed here. ${ }^{4,27,32,33}$

For the fragment ions with low KER under the intense femtosecond laser field, it is unusually ascribed to such a DI process in which the neutral molecules can be ionized to the singly charged parent ions, and then each ion can dissociate into a neutral fragment and a singly charged fragment ion by the rest laser energy or the repulsive states of the singly charged parent ions. ${ }^{4,27,32,33}$ In this DI process, the KERs of the fragment ions are usually relative low. Thus, the fragment ions $\mathrm{H}_{3}{ }^{+}(0.96$
eV) and $\mathrm{CHO}^{+}(0.09 \mathrm{eV})$ with relative low KERs can be respectively assigned to the DI processes

$$
\begin{aligned}
& \mathrm{CH}_{3} \mathrm{OH}^{+} \rightarrow \mathrm{CHO}+\mathrm{H}_{3}^{+}, \\
& \mathrm{CH}_{3} \mathrm{OH}^{+} \rightarrow \mathrm{H}_{3}+\mathrm{CHO}^{+} .
\end{aligned}
$$

Similarly, the fragment ions $\mathrm{H}_{2} \mathrm{O}^{+}(0 \mathrm{eV})$ and $\mathrm{CH}_{2}{ }^{+}(0.25 \mathrm{eV})$ with relative low KERs, can also be respectively assigned to the DI processes

$$
\begin{aligned}
& \mathrm{CH}_{3} \mathrm{OH}^{+} \rightarrow \mathrm{CH}_{2}+\mathrm{H}_{2} \mathrm{O}^{+}, \\
& \mathrm{CH}_{3} \mathrm{OH}^{+} \rightarrow \mathrm{H}_{2} \mathrm{O}+\mathrm{CH}_{2}{ }^{+},
\end{aligned}
$$

Thus, the four DI processes are securely confirmed in the experiment. $\mathrm{Xu}$ and co-workers studied the hydrogen migration process of methanol dication to $\mathrm{H}_{2} \mathrm{O}^{+}+\mathrm{CH}_{2}{ }^{+}$by a pump-probe coincidence momentum imaging method, and their experimental results showed that this hydrogen migration process in the singly charged methanol could occur within the ultrashort laser field $(\sim 38 \mathrm{fs}) \cdot{ }^{14}$ Ekanayake and co-workers studied the formation of $\mathrm{H}_{3}{ }^{+}$from methanol dication through analysis of femtosecond time-resolved strong-field ionization and photoion-photoion coincidence measurements, and they found this hydrogen migration could occur in the $\sim 100$ fs timescale. ${ }^{16}$ Considering our pulse duration of $120 \mathrm{fs}$, it could be deduced that the dissociation process of methanol to fragment ions $\mathrm{H}_{2} \mathrm{O}^{+}$and $\mathrm{H}_{3}{ }^{+}$could occur within our laser pulse. Therefore, this entire DI process can be interpreted as: femtosecond laser pulse leads to a vertical ionization of neutral methanol into a repulsive region of the potential energy hyper surface of the singly charged methanol, so that a relaxation to the local minimum of methanol monocation $\mathrm{CH}_{3} \mathrm{OH}^{+}$can take place afterward. This structure rearrangement involves rotation of $\mathrm{CH}_{3}$ group along C-O bond, as shown in Fig. 2. Then, the dissociation of $\mathrm{CH}_{3} \mathrm{OH}^{+}$ into $\mathrm{H}_{3}^{+}, \mathrm{CHO}^{+}, \mathrm{H}_{2} \mathrm{O}^{+}$and $\mathrm{CH}_{2}{ }^{+}$take place on the ground

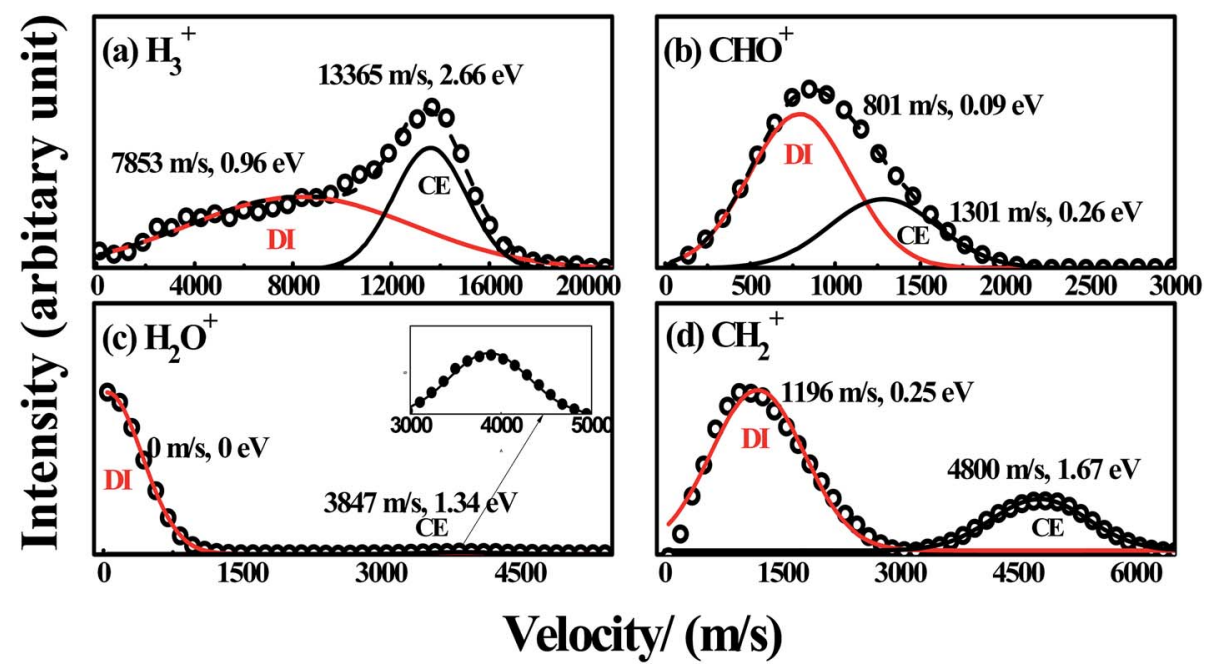

Fig. 5 The velocity distributions of $\mathrm{H}_{3}{ }^{+}, \mathrm{CHO}^{+}, \mathrm{H}_{2} \mathrm{O}^{+}$and $\mathrm{CH}_{2}{ }^{+}((\mathrm{a})-(\mathrm{d}))$ with laser intensity of $1.2 \times 10^{14} \mathrm{~W} \mathrm{~cm}{ }^{-2}$. The black circles (O) are experimental data, the black (-) and red solid lines (-) are simulated results for CE and DI channels with multi-peak Gaussian functions, the black dash lines in (a) and (b) are the sum of the fitted Gaussian functions. 
doublet PES of $\mathrm{CH}_{3} \mathrm{OH}^{+}$with presence of the laser field, and hydrogen migration and intramolecular rearrangement processes proceed the actual reaction process.

\section{Conclusions}

In this paper, we demonstrated theoretically and experimentally that hydrogen migration pathways leading to $\mathrm{H}_{3}{ }^{+}+\mathrm{CHO}, \mathrm{CHO}^{+}$ $+\mathrm{H}_{3}, \mathrm{H}_{2} \mathrm{O}^{+}+\mathrm{CH}_{2}$, and $\mathrm{CH}_{2}^{+}+\mathrm{H}_{2} \mathrm{O}$ could happen in methanol monocation. The $a b$ initio calculation results showed that a neutral $\mathrm{H}_{2}$ moiety in methanol monocation $\mathrm{CH}_{3} \mathrm{OH}^{+}$was the origin to the formation of $\mathrm{H}_{3}{ }^{+}$, and the dissociation pathways leading to $\mathrm{H}_{3}{ }^{+}$and $\mathrm{H}_{2} \mathrm{O}^{+}$were more difficult to happen than that of $\mathrm{CHO}^{+}$and $\mathrm{CH}_{2}{ }^{+}$, and hydrogen migration processes were involved in these dissociation processes. By using dc-slice imaging technique under $800 \mathrm{~nm}$ femtosecond laser field, the corresponding velocity distributions of these fragment ions were calculated from the sliced images of these fragment ions. The presence of low-velocity components of these four fragment ions illustrated the absence of CE in the formation process of these ions. Thus, the four pathways associated with hydrogen migration were securely confirmed from methanol monocation: $\mathrm{CH}_{3} \mathrm{OH}^{+}$to $\mathrm{H}_{3}{ }^{+}+\mathrm{CHO}, \mathrm{CHO}^{+}+\mathrm{H}_{3}, \mathrm{H}_{2} \mathrm{O}^{+}+\mathrm{CH}_{2}$, and $\mathrm{CH}_{2}{ }^{+}+$ $\mathrm{H}_{2} \mathrm{O}$. It could be observed that the ion yields of fragment ions $\mathrm{H}_{3}{ }^{+}$and $\mathrm{H}_{2} \mathrm{O}^{+}$were lower than that of $\mathrm{CHO}^{+}$and $\mathrm{CH}_{2}{ }^{+}$in timeof-flight mass spectrum of methanol. This was consistent with the theoretical results that dissociation from methanol monocation to $\mathrm{H}_{3}^{+}$and $\mathrm{H}_{2} \mathrm{O}^{+}$were more difficult to happen than that of $\mathrm{CHO}^{+}$and $\mathrm{CH}_{2}^{+}$. Our next goal is to study the time evolution of $\mathrm{H}_{3}{ }^{+}, \mathrm{CHO}^{+}, \mathrm{H}_{2} \mathrm{O}^{+}$, and $\mathrm{CH}_{2}^{+}$with isotopically labeled methanol by pump-probe measurements. Ultimately, such experiments would provide further tests of the mechanism proposed in this paper. We hope that the current conclusions stimulate the future work on time evolution of the four fragment ions.

\section{Conflicts of interest}

There are no conflicts to declare.

\section{Acknowledgements}

This work was supported by National Natural Science Foundation of China (Grant No. 11747111), University Students' Innovation and Entrepreneurship Training Program of Xi'an Shiyou University (201810705019), and Natural Science Basic Research Plan in Shanxi Province of China (Grant No. 2016JQ1027). The authors wish to acknowledge Prof. Zhenrong Sun and Dr Yan Yang of East China Normal University for their help on experimental design.

\section{References}

1 K. Yamanouchi, Science, 2002, 134, 1659.

2 Progress in Ultrafast Intense Laser Science I-III, ed. K. Yamanouchi, S. L. Chin, P. Agostini, and E. Ferrante, Springer-Verlag, Berlin, 2006-2008.
3 P. M. Kraus, M. C. Schwarzer, N. Schirmel, G. Urbasch, G. Frenking and K. M. Weitzel, J. Chem. Phys., 2011, 134, 114302.

4 H. Wu, H. Wang, Z. H. Guo and J. Q. Wen, Int. J. Quantum Chem., 2018, 118(22), e25764.

5 R. Itakura, P. Liu, Y. Furukawa, T. Okino, K. Yamanouchi and H. Nakano, J. Chem. Phys., 2007, 127, 104306.

6 H. L. Xu, T. Okino, K. Nakai, K. Yamanouchi, S. Roither, X. H. Xie, D. Kartashov, M. Schöffler, A. Baltuska and M. Kitzler, Chem. Phys. Lett., 2010, 484, 119-123.

7 H. L. Xu, T. Okino and K. Yamanouchi, Chem. Phys. Lett., 2009, 469, 255-260.

8 H. L. Xu, T. Okino and K. Yamanouchi, J. Chem. Phys., 2009, 131, 151102.

9 S. De, J. Rajput, A. Roy, P. N. Ghosh and C. P. Safvan, Phys. Rev. Lett., 2006, 97, 213201.

10 T. Okino, Y. Furukawa, P. Liu, T. Ichikawa, R. Itakura, K. Hoshina, K. Yamanouchi and H. Nakano, J. Phys. B: At., Mol. Opt. Phys., 2006, 39, S515-S521.

11 T. Ando, A. Iwasaki, K. Nakai and K. Yamanouchi, International Conference on Ultrafast Phenomena, 2016.

12 H. L. Xu, T. Okino, T. Kudou, K. Yamanouchi, S. Roither, M. Kitzler, A. Baltuska and S. L. Chin, J. Phys. Chem. A, 2012, 116, 2686-2690.

13 H. L. Xu, C. Marceau, K. Nakai, T. Okino, S. L. Chin and K. Yamanouchi, J. Chem. Phys., 2010, 133, 071103.

14 T. Ando, A. Shimamoto, S. Miura, A. Iwasaki, K. Nakai and K. Yamanouchi, Commun. Chem., 2018, 380, 34.

15 K. Nakai, T. Kono and K. Yamanouchi, J. Chem. Phys., 2013, 139, 181103.

16 N. Ekanayake, M. Nairat, B. Kaderiya, P. Feizollah, B. Jochim, T. Severt, B. Berry, K. R. Pandiri, K. D. Carnes, S. Pathak, D. Rolles, A. Rudenko, I. B. Itzhak, C. A. Mancuso, B. S. Fales, J. E. Jackson, B. G. Levine and M. Dantus, Sci. Rep., 2017, 7, 4703.

17 N. Ekanayake, T. Severt, M. Nairat, N. P. Weingartz, S. M. Farrisi, B. Kaderiya, P. Feizollah, B. Jochim, F. Ziaee, K. Borne, K. P. Raju, K. D. Carnes, D. Rolles, A. Rudenko, B. G. Levine, J. E. Jackson, I. B. Itzhak and M. Dantus, Nat. Commun., 2018, 9, 5186.

18 W. J. Bouma, R. H. Nobes and L. Radom, J. Am. Chem. Soc., 1982, 104, 2929-2930.

19 W. J. Bouma, J. K. Macleod and L. Radom, J. Am. Chem. Soc., 1982, 104, 2930-2931.

20 N. L. Ma, B. J. Smith, J. A. Pople and L. Radom, J. Am. Chem. Soc., 1991, 113, 7903-7912.

21 B. Thapa and H. B. Schlegel, J. Phys. Chem. A, 2014, 118, 1769-1776.

22 D. Townsend, M. P. Minitti and A. G. Suits, Rev. Sci. Instrum., 2003, 74, 2530-2539.

23 M. J. Frisch, G. W. Trucks, H. B. Schlegel, G. E. Scuseria, M. A. Robb, J. R. Cheeseman, G. Scalmani, V. Barone, B. Mennucci, G. A. Petersson, H. Nakatsuji, M. Caricato, X. Li, H. P. Hratchian, A. F. Izmaylov, J. Bloino, G. Zheng, J. L. Sonnenberg, M. Hada, M. Ehara, K. Toyota, R. Fukuda, J. Hasegawa, M. Ishida, T. Nakajima, Y. Honda, O. Kitao, H. Nakai, T. Vreven, J. A. Montgomery Jr, 
J. E. Peralta, F. Ogliaro, M. Bearpark, J. J. Heyd, E. Brothers, K. N. Kudin, V. N. Staroverov, T. Keith, R. Kobayashi, J. Normand, K. Raghavachari, A. Rendell, J. C. Burant, S. S. Iyengar, J. Tomasi, M. Cossi, N. Rega, J. M. Millam, M. Klene, J. E. Knox, J. B. Cross, V. Bakken, C. Adamo, J. Jaramillo, R. Gomperts, R. E. Stratmann, O. Yazyev, A. J. Austin, R. Cammi, C. Pomelli, J. W. Ochterski, R. L. Martin, K. Morokuma, V. G. Zakrzewski, G. A. Voth, P. Salvador, J. J. Dannenberg, S. Dapprich, A. D. Daniels, O. Farkas, J. B. Foresman, J. V. Ortiz, J. Cioslowski, and D. J. Fox, Gaussian 09, Revision B.01, Gaussian, Inc., Wallingford CT, 2010.

24 A. D. Becke, J. Chem. Phys., 1993, 98, 5648-5652.

25 C. Lee, W. Yang and R. G. Parr, Phys. Rev. B: Condens. Matter Mater. Phys., 1988, 37, 785-789.

26 H. Wu, S. A. Zhang, J. Zhang, Y. Yang, L. Deng, T. Q. Jia, Z. G. Wang and Z. R. Sun, J. Phys. Chem. A, 2015, 119, 2052-2057.

27 Y. Yang, L. L. Fan, S. Z. Sun, J. Zhang, Y. T. Chen, S. A. Zhang, T. Q. Jia and Z. R. Sun, J. Chem. Phys., 2011, 135, 064303.
28 Y. X. Zhao, X. N. Wu, J. B. Ma, S. G. He and X. L. Ding, J. Phys. Chem. C, 2010, 114, 12271-12279.

29 X. N. Wu, Y. X. Zhao, W. Xue, Z. C. Wang, S. G. He and X. L. Ding, Phys. Chem. Chem. Phys., 2010, 12, 3984-3997.

30 S. Feyel, J. Döbler, R. Hoeckendorf, M. K. Beyer, J. Sauer and H. Schwarz, Angew. Chem., Int. Ed., 2008, 47, 1946-1950.

31 H. Ren, C. Wu, R. Ma, H. Yang, H. Jiang and Q. Gong, Int. J. Mass Spectrom., 2002, 219, 305-313.

32 Y. M. Wang, S. Zhang, Z. R. Wei and B. Zhang, J. Phys. Chem. A, 2008, 112, 3846-3851.

33 Y. M. Wang, S. Zhang, Z. R. Wei and B. Zhang, Chem. Phys. Lett., 2009, 468, 14.

34 L. A. Curtiss, K. Raghavachari, G. W. Trucks and J. A. Pople, J. Chem. Phys., 1991, 94, 7221.

35 O. Wiest, J. Mol. Struct.: THEOCHEM, 1996, 368, 39.

36 T. S. Zyubina, S. H. Lin, A. D. Bandrauk and A. M. Mebel, Chem. Phys. Lett., 2004, 393, 470.

37 T. S. Zyubina, G. S. Kim, S. H. Lin, A. M. Mebel and A. D. Bandrauk, Chem. Phys. Lett., 2002, 359, 253. 